\title{
PROJETO VER-SUS/BRASIL NO ESTADO DO TOCANTINS: PROTAGONISMO ESTUDANTIL EM DEFESA DO SUS, DA DEMOCRACIA E DOS DIREITOS SOCIAIS
}

Project VER-SUS Brasil in the state of Tocantins - Student's protagonism in defense of the SUS, the democracy and the social rights

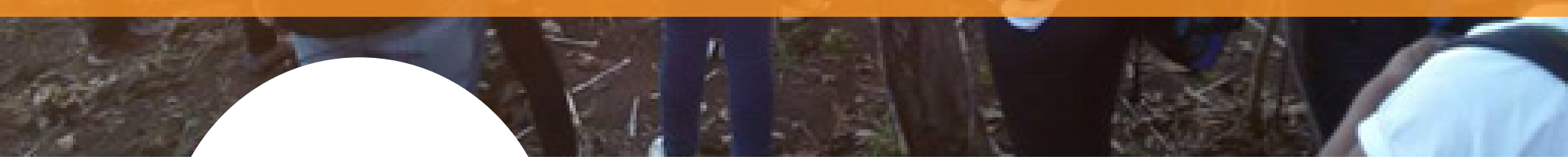

Marta Azevedo Santos ${ }^{1}$

Gilmara Apolinario Reis ${ }^{2}$

Fabiane Santos Barros ${ }^{3}$

Karinne Rocha Gomes ${ }^{4}$

RESUMO

O projeto"VER-SUS/Brasil: Vivências e estágios na realidade do Sistema Único de Saúde" é uma proposta do Ministério da Saúde em parceria com a Associação Brasileira Rede Unida e com diversas entidades representativas e instituições que mantêm um compromisso social e político com o SUS. Especialmente no Tocantins, o projeto se iniciou a partir do movimento estudantil com o apoio de instituições das áreas da educação e saúde e dos movimentos sociais. Propõe-se a imergir os estudantes de diversos cursos da graduação, em especial da área da saúde, no cotidiano do SUS, nas comunidades indígenas e quilombolas e nos movimentos sociais. Pretende fazê-lo através dos cenários de lutas das populações historicamente excluídas como um instrumento para a formação de futuros profissionais do SUS, pautados pela construção de um projeto de sociedade includente, democrática e plural. A partir da pedagogia problematizadora, debates, oficinas e rodas de conversa, graduandos de diversas áreas, profissionais do SUS, coletivos e comunidades envolvidas no projetoassociam o ensino e suas repercussões sobre o trabalho, 0 sistema de saúde, os saberes populares, a participação social e a transdisciplinaridade à construção do conhecimento inter-

\footnotetext{
1 Doutora em Psicologia pela Universidade de Sevilla na Espanha. Professora Adjunta na Universidade Federal do Tocantins. E-mail: mar-azevedo @ hotmail.com

${ }^{2}$ Graduada em Enfermagem pela Universidade Federal do Tocantins. Técnica Administrativa na Universidade

Federal do Tocantins. E-mail: gil_apr@uft.edu.br

${ }^{3}$ Discente em Enfermagem pela Universidade Federal do Tocantins.

E-mail: fabianenfermagem@uft.edu.br

${ }^{4}$ Discente em Enfermagem pela Universidade Federal do Tocantins.

E-mail:karinnerocha77@gmail.com
} 
setorial. O diferencial do projeto reside no protagonismo estudantil que organiza, mobiliza e contribui com o processo político-pedagógico, fortalecendo uma aprendizagem significativa e autônoma, reafirmando a saúde como direito social universal, gratuito e de qualidade. Também estimula o envolvimento dos diversos atores sociais e políticos na luta em defesa do SUS e da democracia, promovendo a formação de profissionais comprometidos ético-politicamente com as necessidades de saúde da população.

Palavras chave: Extensão universitária. Educação popular em saúde. Educação permanente em saúde.

\section{ABSTRACT}

The project "VER-SUS/Brasil in Tocantins state: Experiences and stages in the reality of the Unified Health System" is a tender of the Health Ministry in partnership with "Associação Brasileira Rede Unida" and with many representative organizations and institutions that maintain social and politic commitment with SUS (Unified Health System). Especially in Tocantins, the project started with the student movement, supported by educational and health institutions, as well as by social movements. It is proposed to immerse students from different undergraduate courses, mainly from health area, into SUS' daily routine, indigenous communities, "quilombolas" communities and social movements. It is intended to do so through scenarios of fight of the historically excluded populations as a tool to train SUS' future professionals, grounded in the construction of an inclusive, democratic and plural society project. Based on the problematization pedagogy, debates, workshops, and conversation circles, undergraduates from several areas, SUS' professionals, collectives, and communities enrolled in the project link the teaching process and its repercussions about the work, health system, common knowledge, social participation and transdisciplinarity to the construction of the intersectoral knowledge. The differential of the project remains at the student protagonism, which organizes, mobilizes, and contributes to the political-pedagogic process, strengthening a significant and autonomous learning, reaffirming health as a universal, unpaid and quality social right. It also stimulates the enrollment of diverse social and political actors in defense of SUS and democracy, promoting the qualification of professionals ethical-political committed to the population's health needs.

Keywords: University extension. Popular education in health. Permanent Education in health. 
INTRODUÇÃO

O projeto "VER-SUS/Brasil: vivências e estágios na realidade do Sistema Único de Saúde", em sua primeira versão como projeto nacional, foi organizado a partir de 2004, quando o Ministério da Saúde convidou as Executivas e Representações Nacionais de Estudantes dos cursos de graduação da área da saúde para a construção de uma proposta transformadora que pudesse oportunizar aos atores envolvidos vivenciar e debater acerca da realidade do Sistema Único de Saúde. A partir de 2012 o projeto ampliou seu alcance e atualmente o VER-SUS já ocorreu em 21 estados (AM, PA, TO, MS, MT, GO, SP, MG, RJ, PI, MA, CE, RN, PB, PE, AL, BA, SE, PR, SC, RS) e no Distrito Federal, envolvendo mais de 450 municípios e 10 mil participantes, entre viventes e facilitadores (ASSOCIAÇÃO BRASILEIRA REDE UNIDA, 2016).

O VER-SUS é realizado como uma vivência interdisciplinar na qual os estudantes entram em contato com o trabalho de diferentes profissionais e assim são construídos conhecimentos e práticas que dizem respeito a questões que ultrapassam a formação específica de cada curso, chegando a um terreno interdisciplinar, ético e político. Esse formato é diferente do modo como estamos acostumados a conceber um estágio curricular, que se caracteriza como um período de aprendizado de determinada profissão, no qual o estudante se familiarizará apenas com os procedimentos técnicos de sua área de atuação. (MENDES et al., 2012).

A partir da proposta nacional do VER-SUS, localmente cada vivência se reinventa e agrega elementos que singularizam as experiências. No Tocantins, o protagonismo estudantil foi fundamental nesse processo, oxigenando, organizando, mobilizando e contribuindo para a construção político-pedagógica durante as vivências e na promoção de uma aprendizagem empoderada, significativa e autônoma. A organização local do projeto no estado entende que para alcançar uma educação transformadora não é suficiente apenas conhecer os serviços organizativos do SUS, é preciso discutir as iniquidades, as relações socioeconômicas e políticas transversais ao acesso e à qualidade da saúde pública no Brasil.

Em janeiro de 2015, ocorreu na capital do estado, Palmas, a primeira edição de vivências no SUS e em seus territórios de abrangência, e desde então já foram realizadas quatro edições (2015/1, 2015/2, 2016/1 e 2016/2). Entre 2015 e 2016,cerca de 120 estudantes de diversos cursos da área da saúde, provenientes de diversas instituições públicas e privadas de todo o estado e de outras regiões do país, tiveram a oportunidade de vivenciar a realidade do SUS em Palmas/TO, além de correlacionar a realidade das comunidades indígenas, quilombolas, e dos movimentos sociais como o Movimento dos Trabalhadores Rurais Sem Terra (MST), organizações feministas, LGBTT e antirracistas. 


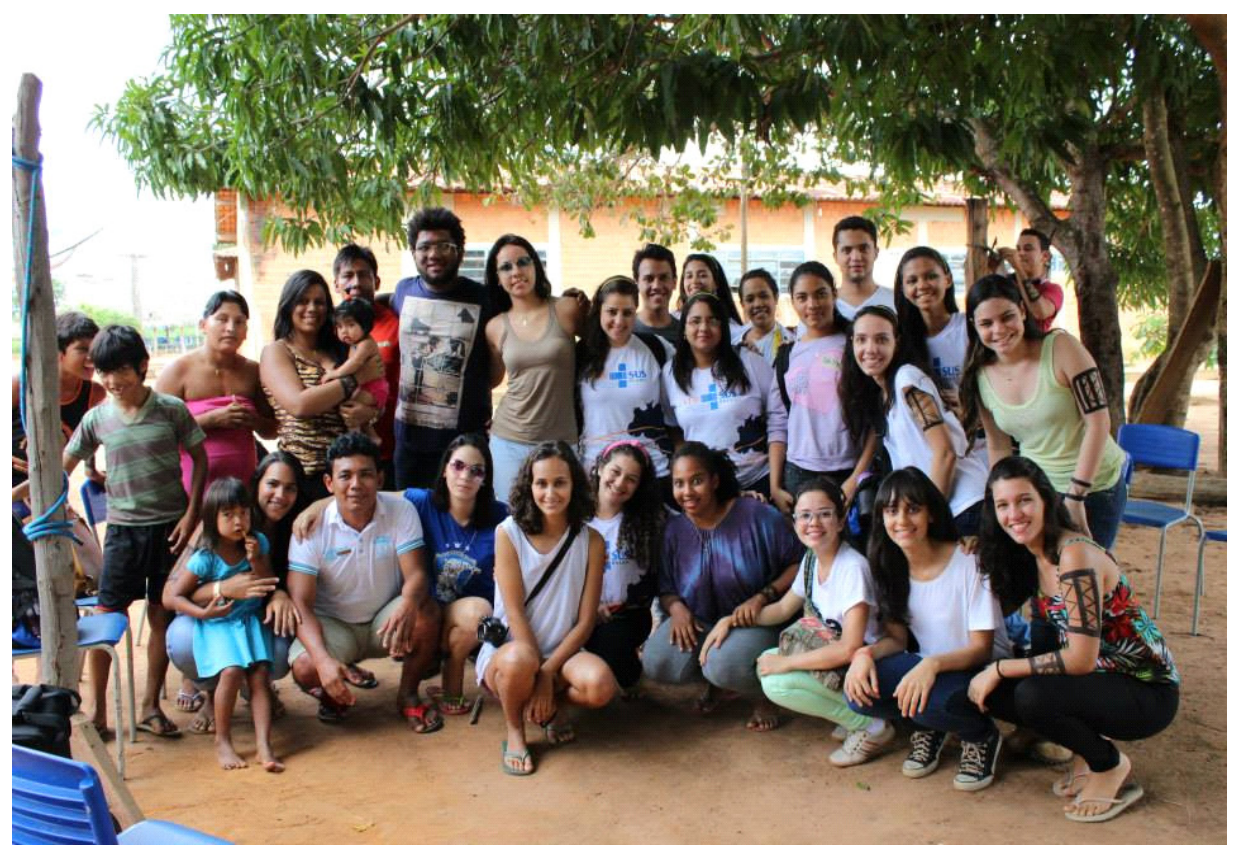

Fonte: Fotografia tirada pela comissão organizadora.
Figura 1

$1^{\text {a }}$ edição VER-SUS/TO (2015/1), durante visita à aldeia indígena Salto da etnia Xerente.

Entre os dias 22 e 23 de junho de 2016, foi realizado na Universidade Federal do Tocantins, o I Seminário do VER-SUS no Tocantins,tendo como tema "O Protagonismo Estudantil em Defesa do SUS e da Democracia". Teve como objetivo socializar as vivências, discutir os desafios, os caminhos percorridos, os resultados da construção do projeto no estado e as perspectivas para o Sistema Único de Saúde na conjuntura social e política atual. Reuniu efetivamente cerca de 400 participantes, incluindo ouvintes, mediadores, colaboradores, representantes de movimentos sociais, povos indígenas e o Movimento dos Trabalhadores Rurais Sem Terra (MST).

A programação abordou temáticas sociopolíticas transversais ao fortalecimento do Sistema Único de Saúde: Saberes e práticas populares de saúde com a participação do pajé Caiapó no espaço intitulado "Tenda do Conto". Práticas integrativas de saúde com as oficinas de massoterapia Ayurveda e Lian Gong; Educação popular em saúde com a oficina de teatro do oprimido;Oficinas artísticas e rodas de conversa que discutiram desde a formação para o SUS até a centralidade da participação e do controle social. 
Figura 2

1ํ Seminário do VER-

SUS TO, 22 e 23 de junho de 2016. No espaço intitulado

"Tenda do Conto", com pajé Caiapó.

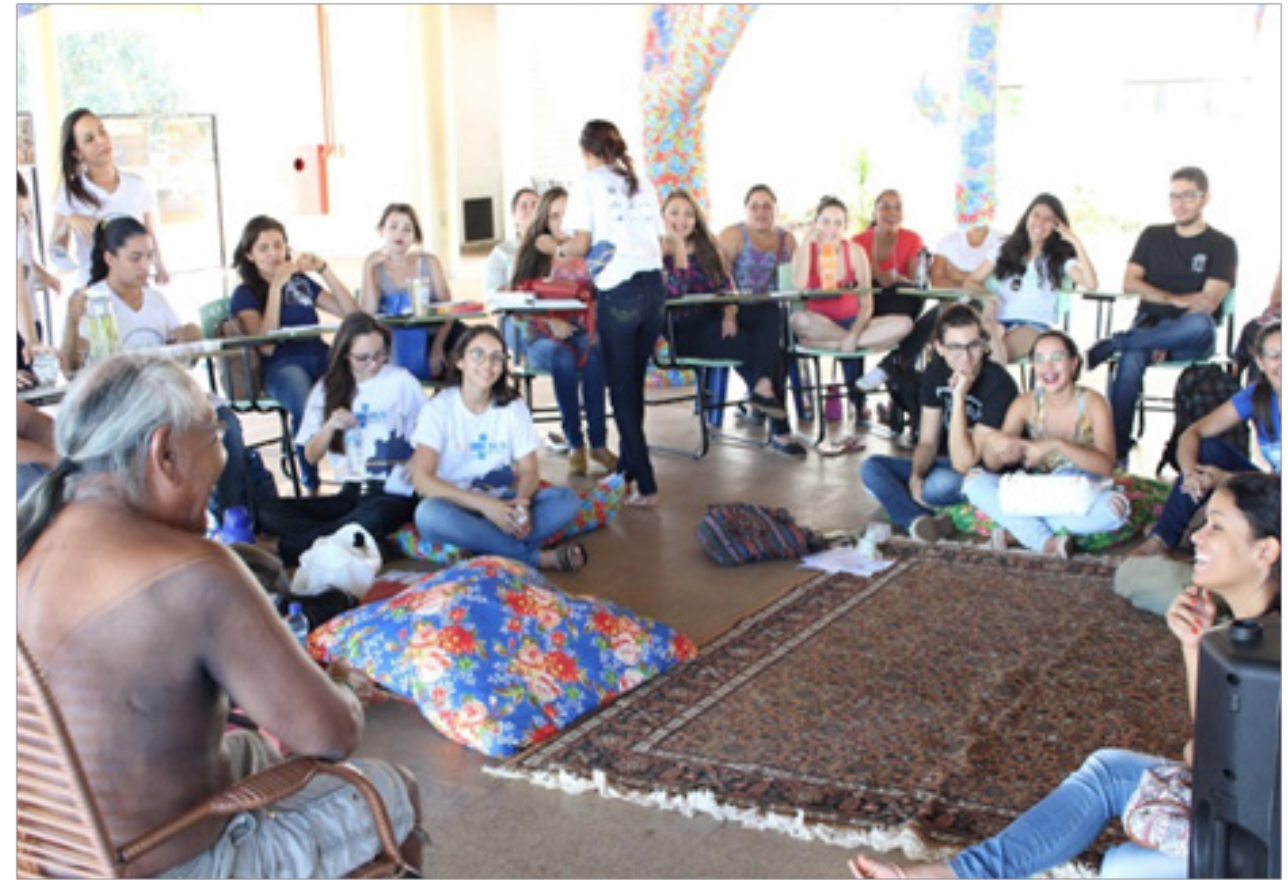

Fonte: Fotografia tirada pela comissão organizadora.

\section{FUNDAMENTAÇÃO TEÓRICA}

A reorientação do modelo assistencial no Brasil impõe a necessidade de reformulações no processo de formação de seus profissionais, estreitando concepção e execução do trabalho, tendo a práxis como recurso didático pedagógico. As metodologias de ensino devem ter como objetivo a transformação das práticas profissionais e da própria organização do trabalho, estruturando-se a partir da problematização sobre a capacidade de acolhimento e cuidado às várias dimensões e necessidades em saúde das pessoas, dos coletivos e das populações (BRASIL, 2004a).

Esta recondução é incorporada nos cursos da saúde em 2004, a partir da criação da Política Nacional de Educação Permanente em Saúde, sendo esta um marco decisivo para a articulação e integração entre ensino, serviço e comunidade, a partir do desenvolvimento de iniciativas qualificadas ao enfrentamento das necessidades e dificuldades do SUS (BRASIL, 2009). A Educação Permanente, diferentemente da Educação Continuada, considera que a formação das pessoas acontece onde há práticas educativas, e estas ocorrem em qualquer lugar, não apenas em escolas ou universidades, ademais as práticas educativas também constroem determinadas culturas. (MARANHÃO, 2015).

Nesta perspectiva o movimento estudantil tem provocado mudanças no cenário de formação, passando a ocupar espaços que potencializam a reflexão crítica, e criam um olhar diferenciado para a universidade, trazendo outras demandas quanto à sua política pedagógica (KLAFKE et al, 2013). A interferência estudantil organizada, não apenas é capaz de mobilizar po- 
deres e interpor conceitos à sociedade, como marca um modo peculiar de existir no mundo que exige transformações sociais (BRASIL, 2004b).

Uma forma de inserir os estudantes nos cenários de prática e atuação é através da extensão universitária. Segundo Falcão (2014), a extensão é considerada a área acadêmica mais dinâmica e viva, capaz de oxigenar a produção do conhecimento e fazer valer a missão social da universidade, em que a preocupação não está apenas em formar profissionais técnicos, mas também para participar da construção da cidadania. Desta forma, um projeto de extensão baseado em vivências tem impactos importantes para a interação dos futuros profissionais com a comunidade, despertando-os para uma formação cidadã que garanta autonomia para buscar e reivindicar seus direitos.

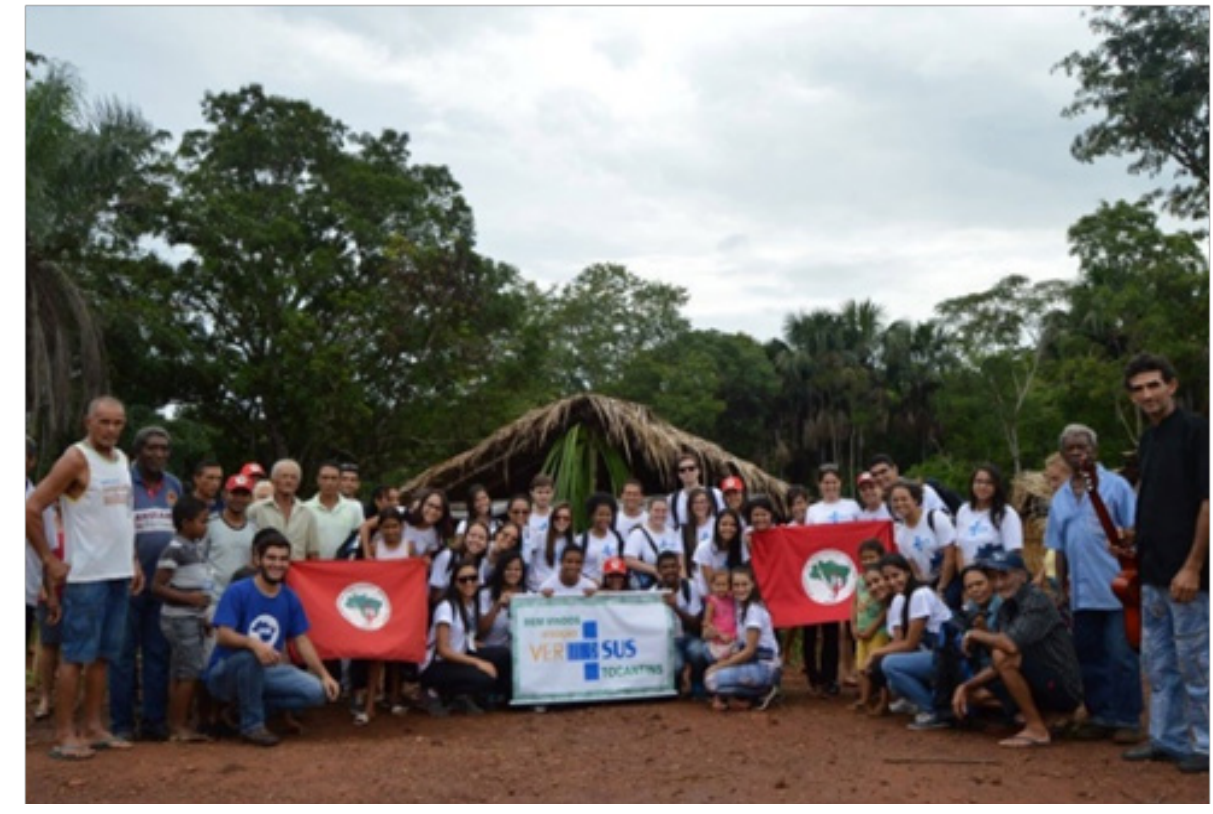

Fonte: Fotografia tirada pela comissão organizadora.
Figura 3

$3^{\text {a }}$ edição VER-SUS/TO (2016/1). Durante a visita ao acampamento do MST no distrito de Buritirana.

Os programas de extensão universitária são importantes para a aproximação e troca de conhecimentos e experiências entre alunos e população, pela possibilidade de desenvolvimento de processos de ensino-aprendizagem a partir de práticas com o ensino e pesquisa e, especialmente, pelo fato de propiciar o confronto da teoria com o mundo real de necessidades e desejos (HENNINGTON, 2005).

Nesta perspectiva, Freire (1996) destaca as metodologias ativas como importantes ferramentas pedagógicas que aproximam a epistemologia da prática e favorecem uma relação dialógica entre educador e educando, reafirmando ainda seu compromisso com uma formação crítica, cidadã, autônoma, significativa, holística e humanizadora, que valoriza os saberes populares e os conhecimentos construídos no âmbito das comunidades. 
Utilizando a metodologia da problematização, o VER-SUS é uma estratégia condutora para aprendizagem, contribuindo para estimular os estudantes à crítica e à reflexão sobre as diferentes conjunturas, provocando mudança de visão e de comportamento perante o sistema, portanto a formação deve dialogar com outros saberes científicos e populares, despertando o exercício da transformação da realidade de saúde vigente no país (VALENÇA, 2014).

\section{METODOLOGIA}

As vivências do projeto VER-SUS propõem-se a imergir estudantes de diversos cursos da graduação, em especial da área da saúde, no cotidiano do SUS. Localmente essa experiência foi ampliada pela interface com as comunidades indígenas, quilombolas e movimentos sociais, transformando os cenários de lutas das populações historica $\neg$ mente excluídas em um instrumento para a formação de futuros profissionais do SUS pautados pela construção de um projeto de sociedade includente, democrática e plural.

Durante a imersão teórica, prática e vivencial no SUS e nos seus territórios de abrangência, os participantes ficam 24 horas por dia, durante todo o período da vivência, que varia entre 7 a 15 dias, disponíveis para as atividades do projeto. No Tocantins a programação incluiu realizadas visitas à rede de atenção, às comunidades e aos movimentos sociais, além de debates, oficinas e rodas de conversa diariamente. Desta forma, os atores envolvidos associam o ensino e suas repercussões sobre o trabalho, o sistema único de saúde, os saberes populares, a participação social e a transdisciplinaridade para a construção do conhecimento intersetorial.

TO (2016/2). Durante a oficina de arte-terapia.

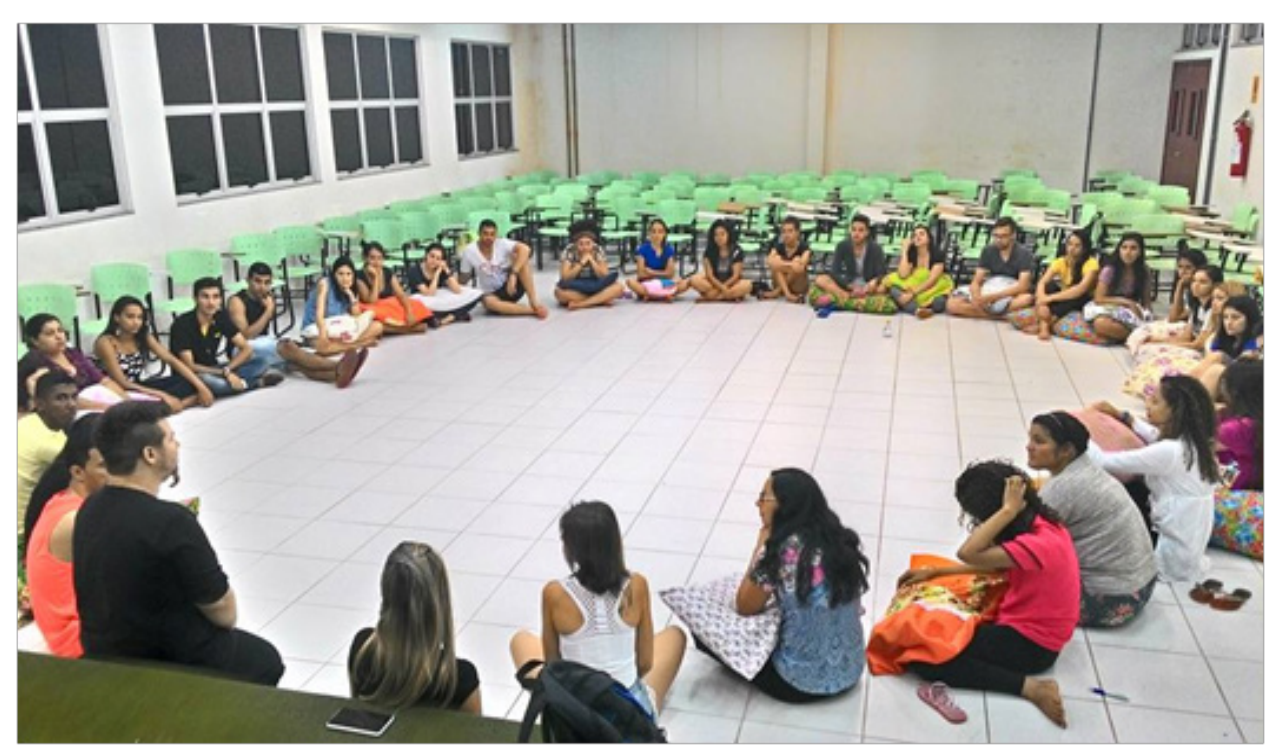

Fonte: Fotografia tirada pela comissão organizadora. 
Em todo o Brasil os participantes são divididos em três categorias, não excludentes entre si: comissão organizadora, facilitadores e viventes. A primeira pode ser composta por coletivos de estudantes, docentes, representantes da gestão municipal ou estadual de saúde, trabalhadores da saúde e representantes da participação popular local. A segunda diz respeito a estudantes de graduação que já participaram de vivências e atuam para contribuir com o processo político-pedagógico do grupo, conduzindo as atividades e visitas que serão realizadas durante a imersão. $O$ terceiro são os estudantes da graduação, residentes, estudantes do ensino técnico na área da saúde, bem como integrantes dos movimentos sociais, que normalmente estão chegando pela primeira vez, interessados em conhecer mais sobre o SUS e qualificar sua formação para atuarem na saúde coletiva (MARANHÃO, 2015).

Durante os dias do projeto, viventes e facilitadores desenvolvem um portfólio, que é um registro critico-reflexivo sobre os cenários, os atores e os sentimentos experimentados durante a imersão. Todos os portfólios podem ser acessados através do site da estação de observação do VER-SUS vinculada à plataforma do Observatório de Tecnologias em Informação e Comunicação em Sistemas e Serviços de Saúde (OTICS). As várias formas de relato, sistematizações e problematizações mostram como as vivências são singulares, mesmo ocorrendo dentro de um mesmo projeto (MARANHÃO, 2015).

A premissa de coletividade desemboca em uma intensa e complexa rede de experiências aglutinadas durante os dias de vivência, onde emoções e sentimentos afloram aos borbotões, exigindo assim, a incorporação de metodologias de grupo a fim de favorecer as relações interpessoais durante a vivência. No Tocantins optou-se pela "Dinâmica do Anjo", esta se baseia na responsabilização recíproca entre os participantes pelo bem-estar de seus companheiros. Desta forma, cada integrante fica responsável por outro, de quem deve aproximar-se, cuidar e proteger até o final da imersão. Além disto, monta-se o "Mural do Anjo" onde diariamente os participantes podem compartilhar mensagens e elementos de afeto, apoio e motivação entre si, favorecendo a integração, a empatia e a troca positiva durante da vivência. 
Figura 5

3믈 edição VER-SUS/TO

$(2016 / 1)$. Mural para a dinâmica do anjo.

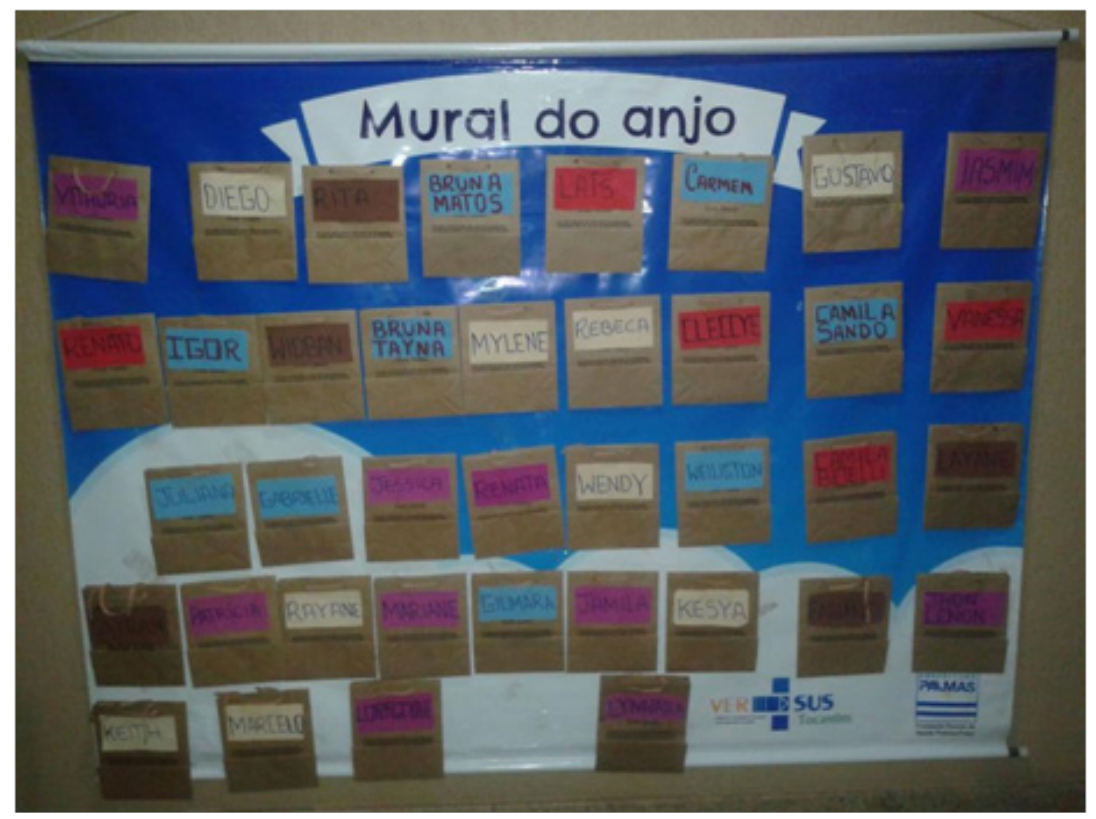

Fonte: Fotografia tirada pela comissão organizadora.

\section{RESULTADOS E DISCUSSÃO}

O projeto VER-SUS, como extensão universitária, é uma experiência que aproxima graduandos, profissionais de saúde, comunidades e movimentos sociais num espaço de trocas de conhecimentos e experiências, visando fortalecer os compromissos éticos, políticos, sociais e profissionais destes atores, com os processos de luta e qualificação do Sistema Único de Saúde.

A reformulação dos processos formativos para os futuros profissionais do SUS deve tomar como princípios fundamentais a interdisciplinaridade, a transdisciplinaridade e a integralidade do cuidado para a inovação em saúde, reafirmando ainda, a necessidade da unidade entre os diversos setores da sociedade a fim de defender o acesso integral, gratuito e de qualidade à saúde no Brasil, através de práticas de saúde e cuidado que incorporem o saber popular e que estejam conectadas com a realidade de vida das pessoas em de todos os âmbitos do SUS (BRASIL, 2004a).

Neste sentido, o VER-SUS como extensão universitária é um elemento fundamental na transformação do processo ensino-aprendizagem, atuando diretamente como elo entre a universidade e a comunidade na construção de caminhos para a promoção social. A passagem por projetos de vivências permite ao graduando a oportunidade de se aproximar da realidade de uma comunidade, observando de maneira crítica todos os aspectos que lhe influenciam (FALCÃO, 2006). 


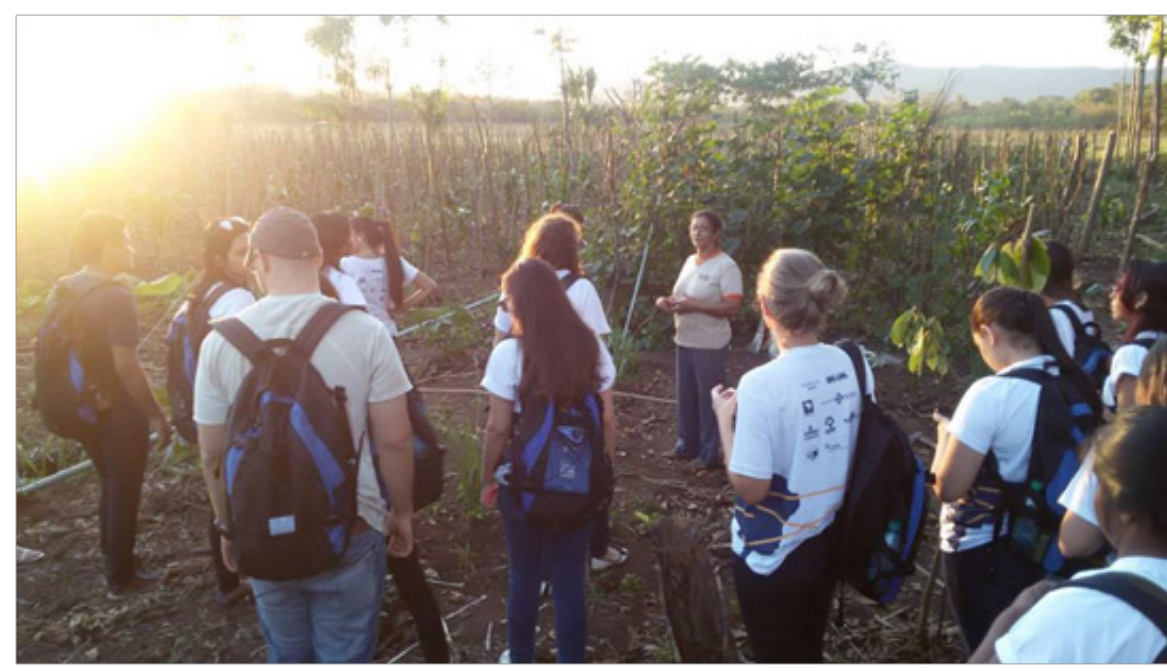

Fonte: Fotografia tirada pela comissão organizadora.
Figura 6

$2^{\text {a }}$ edição VER-SUS/

TO (2015/2). Durante visita a propriedade que utiliza sistema de cultivo agroflorestal sem agrotóxicos no Assentamento São João.

O contexto de reorientação profissional do VER-SUS tem sido uma oportunidade para estudantes, profissionais de saúde, gestores e representantes de movimentos sociais trocarem experiências, ampliarem saberes, socializarem conhecimentos, e assim qualificarem o projeto social e político do SUS. Possibilitando o despertar de uma visão ampliada do conceito de saúde, através da abordagem de temáticas sobre educação permanente em saúde, educação popular em saúde, quadrilátero da formação, aprendizagem significativa, interdisciplinaridade, redes de atenção à saúde, reforma política, feminismo, racismo, LGBTfobia ea luta dos movimentos sociais.

\section{CONCLUSÃO}

A experiência do projeto VER-SUS no estado do Tocantins, nos anos de 2015 e 2016, se destaca pela pluralidade dos atores, dos cenários, das discussões, e dos olhares ampliados sobre o Sistema Único de Saúde e suas realidades circundantes. A imersão de graduandos de diferentes áreas proporcionaram olhares multidisciplinares sobre os serviços de saúde, e o contato com comunidades e movimentos sociais promoveram espaços de construção e desconstrução de saberes pré-estabelecidos.

Vivenciar, observar, sentir e respirar o Sistema Único de Saúde constitui-se como um importante dispositivo que permite aos participantes experimentarem um novo espaço de aprendizagem, aproximando-os do cotidiano de trabalho das organizações e serviços de saúde, entendido enquanto princípio educativo e espaço para desenvolver processos de luta dos setores no campo da saúde, possibilitando a formação de profissionais comprometidos eticamente com os princípios e diretrizes do sistema único de saúde e que se entendam como atores sociais, agentes políticos, capazes de promover transformações (FERLA, A. A. et al, 2013). 
O projeto "VER-SUS: vivências e estágios nas realidades do SUS" se mostra como uma ferramenta capaz de sensibilizar os futuros profissionais do país para o reconhecimento das potencialidades e limitações do Sistema Único de Saúde, trazendo os estudantes para o enfrentamento dos desafios que permeiam a saúde coletiva e a consolidação do SUS. Assim, reafirma a saúde como direito social universal, gratuito e de qualidade, estimulando o envolvimento dos diversos atores sociais e políticos na luta em defesa do SUS e da democracia, além de promover a formação de profissionais comprometidos ético-politicamente com as necessidades de saúde da população.

\section{REFERÊNCIAS}

ASSOCIAÇÃO BRASILEIRA REDE UNIDA. Projetos de vivências: VERSUS BRASIL 2016-2 com inscrições abertas até 17/07. Disponível em: $<$ http://www.redeunida.org.br/noticia/chamada-de-seminarios $>$. Acesso em: 7 mar. 2017.

BRASIL, Ministério da Saúde. Secretaria de Gestão do Trabalho e da Educação na Saúde. AprenderSUS: o SUS e os cursos de graduação da área da saúde. Brasília: Ministério da Saúde, 2004a .

Política Nacional de Educação Permanente em Saúde. Brasília: Ministério da Saúde, 2009.

Ver-SUS Brasil: cadernos de textos. Brasília: Ministério da Saúde, 2004b.

FALCÃO, E. F. Vivência em comunidades: outra forma de ensino. João Pessoa: Ed. Universitária, 2006.

2. ed. . João Pessoa: Editora UFPB, 2014.

FERLA, A.A. et al. VER-SUS Brasil: cadernos de textos. Porto Alegre: Rede Unida, 2013.

FREIRE, P. Pedagogia da autonomia: saberes necessários à prática educativa. Ed. Sabota São Paulo, 1996.

HENNINGTON, E. A. Acolhimento como prática interdisciplinar num programa de extensão universitária. Cad. Saúde Pública. Rio de Janeiro, v.21, n.1, p. 256-265, jan./fev. 2005.

KLAFKE, T. E.; ARAÚJO, B. R.; CARDOSO, C. G. Formação em Saúde e Protagonismo Estudantil: Grupo de Estudos e Trabalhos em Saúde Coletiva.

Psicol. Ensino \& Form. Brasília, v. 4, n. 1, p. 3-19, 2013. 
MARANHÃO, T. Função-facilitador (a) nos estágios e vivências na realidade do Sistema Único de Saúde: marcas de protagonismo estudantil na construção de práticas formativas. Porto Alegre: Rede Unida, 2015.

MENDES, F. M. S. et al . VER-SUS: relato de vivências na formação de Psicologia. Psicol. Cienc. Prof. Brasília, v. 32, n. 1, p. 174-187, 2012.

VALENÇA, C. N. et al. Articulação teoria/prática na formação em saúde e a realidade do Sistema Único de Saúde. Rev. Enferm. UERJ, Rio de Janeiro, v. 22, n. 6, p. 830-835, nov./dez. 2014.

Data de recebimento: 14 de abril de 2017.

Data de aceite para publicação: 25 de maio de 2017. 